\title{
EL DESPIDO DISCIPLINARIO POR INCUMPLIMIENTO GRAVE DE LAS OBLIGACIONES LABORALES EN EL ORDENAMIENTO JURÍDICO CHILENO
}

\author{
THE DISCIPLINARY DISMISSAL FOR SERIOUS BREACH \\ OF THE LABOR OBLIGATIONS IN THE CHILEAN LEGAL \\ SYSTEM
}

\author{
ÁLVARO DOMÍNGUEZ MONTOYA* \\ Magíster en Drets Sociolaborals \\ Universidad Autónoma de Barcelona \\ Barcelona - España \\ RODOLFO WALTER DÍAZ** \\ Profesor de Derecho del Trabajo \\ Universidad de Concepción \\ Concepción - Chile
}

\section{RESUMEN}

El presente trabajo tiene por objeto abordar la causal de despido disciplinario fundada en el incumplimiento grave de las obligaciones laborales. Se analizan los aspectos doctrinarios y jurisprudenciales de tal institución, junto a los requisitos que deben concurrir para su procedencia. En este último aspecto, se aborda el incumplimiento de una obligación laboral y su pluralidad de fuentes, su relación con el reglamento interno y el contenido ético del contrato. De

\footnotetext{
* Domínguez Montoya, Álvaro. Abogado. Licenciado en Ciencias Jurídicas y Sociales, Universidad de Concepción, Chile; Magíster en Drets Sociolaborals y doctorando en Derecho, ambos por la Universitat Autónoma de Barcelona, España. aedodominguez@gmail.com.

** Walter Díaz, Rodolfo. Abogado. Licenciado en Ciencias Jurídicas y Sociales, Universidad de Concepción, Chile; Magíster y Doctor en Derecho, ambos por la Universidad Nacional de Rosario, Argentina, Profesor Derecho del Trabajo, Facultad de Ciencias Jurídicas y Sociales, Universidad de Concepción. twalter@udec.cl. Artículo recibido el 13 de noviembre de 2016 y aceptado para su publicación el 24 de enero de 2017. Abreviaturas utilizadas: C.T. (Código del Trabajo); C.A. (Corte de Apelaciones); Corte Suprema (C.S.).
} 
la misma forma se analiza la gravedad del incumplimiento según criterios jurisprudenciales, para finalmente profundizar en las formalidades del despido, oportunidad, impugnación, reparación y reglas procedimentales por las cuales ha de regirse la sustanciación de las acciones para reclamar su legalidad.

Palabras clave: Contrato de trabajo, disciplina; incumplimiento grave de obligaciones; despido.

\section{ABSTRACT}

The aim of this work is to approach the grounds of disciplinary dismissal founded on the serious breach of the labor obligations. There has been analyzed the legal doctrine and jurisprudential aspects as well as the requirements for this purpose. In the latest aspect, it is approached the breach of a labor obligation and its plurality of sources, its relation with the internal regulation and the ethical content of the contract. Also the seriousness of the breach according to jurisprudential criteria, and finally a full study devoted to recognize the formalities, opportunities, challenges, repairements and procedure rules of the dismissal by which must be ruled the justification of the actions so as to claim its legality.

Keywords: Employment contract; discipline; serious breach of obligations; dismissal.

\section{EL DESPIDO DISCIPLINARIO Y ALGUNOS ASPECTOS DOCTRINARIOS DE CONTEXTUALIZACIÓN}

En aquellos casos en que la voluntad de extinción del contrato de trabajo encuentra su origen en la decisión del empleador fundada en la conducta del trabajador, nos situamos dentro de las hipótesis de despido de variante subjetiva ${ }^{1} y$ de naturaleza disciplinaria, ${ }^{2}$ la cual normativamente encuentra de manera genérica su causa más amplia y de mayor identidad en el incumplimiento grave de las obligaciones que impone el contrato de trabajo.

Con el objeto de desentrañar los alcances y limitaciones del despido

\footnotetext{
1 Albiol Montesinos, Ignacio, El despido disciplinario y otras sanciones en la empresa, Ediciones Deusto S.A., Bilbao, 1990, p. 36 y ss.

2 Ideas tomadas de Alonso Olea, Manuel, El despido, Instituto de Estudios Políticos, Ediciones Deusto S.A., Madrid, 1958.
} 
disciplinario, debemos tener en consideración su vinculación con los fundamentos e instituciones que confluyen en su estructuración, esto es, las aprensiones teóricas heredadas del derecho de los contratos (el despido como resolución contractual) y lógica del poder disciplinario propio de quien detenta la titularidad de los medios de producción (el despido como sanción), ${ }^{3}$ ambos "polos de atracción" que han condicionado el debate laboral sobre la naturaleza, fundamentos, efectos y reparación del despido. ${ }^{5}$

Frente a sus contornos, creemos oportuno entroncar el debate del despido por incumplimiento grave de las obligaciones laborales en la lógica de un acto de autotutela y poder privado, ${ }^{6}$ que debe ser observado desde la estructura desigual de la relación laboral en la empresa, como así también el rol que cumplen las formas jurídicas. ${ }^{7}$ En efecto, "el empresario no sólo tiene un derecho como acreedor, a la manera obligacional, sino un derecho de poder, de carácter jurídico personal", ${ }^{8}$ que analizado desde la función ideológica que entraña el Derecho del Trabajo, ${ }^{9}$ evoca un instrumento de justificación de poder que lo hace difuso y lo transfigura en verdad mediante la noción de orden y objetividad, al permitir y condicionar ciertas prácticas y relaciones

3 Alonso Olea, El despido, cit. (n. 2), p. 106 y ss.; Gil y Gil, José L., "El concepto de despido disciplinario", en Martín Jiménez, R.; Sempere Navarro, A. (Coords.), El Despido: aspectos sustantivos y procesales, Editorial Aranzadi, Madrid, 2004, p. 72 y ss.

4 Martín Valverde, Antonio, "Cuestiones actuales sobre el despido disciplinario", en Gárate Castro, Francisco J. (Coord.), Estudios ofrecidos al profesor Manuel Alonso Olea, con motivo de investidura como doctor "honoris causa" por la Universidad de Santiago de Compostela, Santiago de Compostela, 1997, p.18 y ss.

5 V. Alonso Olea, El despido, cit. (n. 2), p. 106 y ss., Gil y Gil, cit. (n. 3), p. 72 y ss. En Chile, Fernández Toledo, Raúl, "El poder disciplinario del empleador: Configuración jurídica de la sanción laboral que puede imponer al trabajador dependiente", Revista de Derecho (P. Universidad Católica de Valparaíso), 2015, Vol. 44, pp. 423-460. Con un mayor detalle, coherencia y fundamentos ver FERnÁndez Toledo, Raúl, El poder disciplinario del empleador, Thomson Reuters - La Ley, Santiago, 2016.

${ }^{6}$ V. Gil y GIL, José L., Autotutela privada y poder disciplinario en la empresa, Ministerio de Justicia, Madrid, 1993.

7 V. Rodríguez-Piñero y Bravo-Ferrer, Miguel, "Derecho, Trabajo y despido", Relaciones laborales. 1997, No 1, pp. 1-9, y Baylos Grau, Antonio; Pérez Rey, Joaquín, El despido o la violencia del poder privado, Trotta, Madrid, 2009.

8 Sinzheimer, Hugo, "La esencia del Derecho del Trabajo", en Sinzheimer, H., Crisis económica y derecho del trabajo; cinco estudios sobre la problemática humana y conceptual del derecho del trabajo, Ministerio de Trabajo y Seguridad Social, Madrid, 1984, p. 75.

9 V. Domínguez Montoya, Álvaro; Mella Cabrera, Patricio, "Trabajo y Derecho: un padre ausente, el conflicto social”, Revista de Derecho Universidad Católica del Norte (RUCN), 2015, vol. 22 № 1, pp. 105-148. 
jerárquicas,${ }^{10}$ ascendiendo el derecho como la máscara del poder. ${ }^{11}$

En este contexto, la empresa se constituye por un conjunto de dispositivos que la transforman en un espacio de disciplinamiento, una institución de sometimiento y sumisión temporal, espacial y física, donde se ejerce por el empleador un poder polimorfo y polivalente de carácter económico, político y judicial, por cuanto es el empleador quien da órdenes, establece reglamentos, expulsa y acepta individuos dentro de su organización, configurando un verdadero derecho al castigo y recompensa ante instancias de enjuiciamiento interno presididas por él. ${ }^{12}$

El despido en tal contexto se presenta como una "acto de fuerza", un "fenómeno de violencia inserto en los itinerarios de la autoridad empresarial", ${ }^{13}$ que incide directamente sobre los derechos de los trabajadores, definiendo negativamente su posición social y económica. ${ }^{14}$ Como acto privado, niega al trabajo como una instancia de "integración y participación en la sociedad, en la cultura, en la educación y en la familia", por cuanto "crea una persona sin calidad social, porque la cualidad de la misma y los referentes que le dan seguridad en su vida social dependen del trabajo". ${ }^{15}$

Por lo mismo, reconociendo la estructura subordinada de la relación laboral y el poder del empleador validado y normalizado jurídicamente por el contrato de trabajo, debemos entender que el despido en su variante disciplinaria expresa un acto de autotutela privada de uno sobre otro, que en el contexto de sumisión y dependencia se formula como un acto de violencia por los efectos que produce. ${ }^{16}$ Es por lo anterior que el Derecho del Trabajo ha pretendido "someterlo a la civilización democrática", racionalizándolo,

\footnotetext{
${ }^{10}$ V. Foucault, Michel, Nietzsche, la Genealogía, la Historia, Pre-textos, Valencia, 2008, pp. 17, 18 y ss.; 36 y ss; Foucault, Michel, Defender la Sociedad. Curso en el Collège de France (1975-1976), FCE, México D.F., 2006, pp. 35, 42, 43; Foucault, Michel, Historia de la Sexualidad. La voluntad del saber, Ed. Siglo XXI, Buenos Aires, 2007, pp. 74 y ss.

${ }^{11}$ En sentido similar, Kahn-Freund señala "el derecho necesita contemplar las relaciones de subordinación en términos de coordinación, esto es presentar un acto de sumisión bajo la máscara de un contrato, porque es a través de esta ficción, como las leyes conjuran la pesadilla del trabajo forzoso". KAHN-FreUnD, Otto, Trabajo y Derecho, Ministerio de Trabajo y Seguridad Social, Madrid, 1987, p. 60.

${ }^{12}$ Foucault, Michel, Vigilar y castigar. Nacimiento de la prisión, Siglo XXI Editores, Buenos Aires, 2002, pp. 153 y ss; Foucault, Michel, La verdad y las formas jurídicas, Gedisa, Barcelona, 1995, pp. 133 y ss.

${ }^{13}$ Baylos Grau y Pérez Rey, cit. (n. 7), p. 44.

${ }^{14}$ Baylos Grau, Antonio, "Consideraciones sobre el despido individual y la garantía judicial del derecho al trabajo", Revista de Derecho Social, 2009, No 46, pp. 11-30.

${ }^{15}$ Baylos Grau y Pérez Rey, cit. (n. 7), pp. 34 a 36.

${ }^{16}$ Ibíd., p. 44 y ss.
} 
procedimentándolo y formalizándolo, "para evitar que se corrompa en pura arbitrariedad". ${ }^{17}$

En esta aproximación aparece evidente la necesidad de encuadrar el despido en la lógica del ejercicio del poder disciplinario del empleador, ${ }^{18}$ el cual tiene verdaderos rasgos punitivos que se expresan en los fundamentos de la sanción que impone. En materia laboral, ésta se encuentra determinada por la finalidad de la medida en su función punitiva, como así también, en el hecho ilícito justificativo, ${ }^{19}$ que según la doctrina clásica obligan a enmarcar la conducta que se considera ilícita dentro de parámetros de adecuación, esto es en un tipo descriptivo, técnica muy propia a la tipicidad del Derecho Penal con sus matizaciones, ${ }^{20}$ exigiendo límites de gradualidad, ponderación, causalidad, control y reparación, como un modelo de garantías ante el ejercicio de tal poder. ${ }^{21}$

Es preciso señalar que esta "tipicidad" o "taxatividad" no debe entenderse justificada en un sentido estrictamente penal, sino más bien se conjuga con otras exigencias constitucionales "derivadas de principios tales como el de seguridad jurídica", el saber a qué atenerse en "materia de causas disciplinarias" en la extinción del contrato de trabajo. ${ }^{22}$

Ahora en este contexto y siguiendo a FERNÁNDEZ, atendiendo que el despido en su variante disciplinaria constituye la más grave sanción laboral, es lógico plantearse si frente a los rasgos punitivos del poder disciplinario del empleador resulta o no aplicable la garantía del debido proceso, o en términos más generales, preguntarnos si es posible extenderla como un núcleo proyectable a todo poder sancionador, sea de naturaleza pública o privada. ${ }^{23} \mathrm{Si}$ entendemos que el poder disciplinario del empleador impone a sus trabajadores

${ }^{17}$ Ibíd., p. 47 y ss.

18 V. CRemades Sanz-Pastor, Bernardo, La sanción disciplinaria en la empresa, Instituto Estudios Políticos, Madrid, 1969, pp. 238 y ss; FernÁndez LóPez, María Fernanda, El poder disciplinario en la Empresa, Civitas, Madrid, 1991, pp. 244; Albiol Montesinos, El despido, cit. (n. 1), p. 36. En Chile, FERNÁNDEZ Toledo, cit. (n. 5), pp. 425 y ss.

${ }^{19}$ V. Fernández López, cit. (n. 18), p. 229; Cremades Sainz-Pastor, cit. (n. 18), p.171; Fernández Toledo, cit. (n. 5), pp. 425 y ss.

${ }^{20}$ Rodríguez-PiÑero y Bravo-Ferrer, Miguel, "El despido disciplinario y la 'modernización' del Derecho del Trabajo", en Gil y Gil, J.; Manuel del Valle, J. (Coords.), El despido disciplinario: Homenaje al Profesor Juan Antonio Sagardoy Bengoechea, Cinca, Madrid, 2009, p. 49.; Alonso Olea, cit. (n. 2), p. 107. En Chile, Fernández Toledo, cit. (n. 5), pp. 425, 426, 440 y ss.

${ }^{21}$ V. Baylos Grau, cit. (n. 14), pp. 11-30.

${ }^{22}$ Gómez Abelleira, Francisco, La Causalidad del Despido Disciplinario, Thomson Reuters, Madrid, 2009, pp. 118 y ss.

${ }^{23}$ Fernández Toledo, cit. (n. 5), pp. 275 y ss. 
verdaderas sanciones privadas con funciones equivalentes a las penas penales y que atiende al hecho mismo de sancionar antes que la calidad del sujeto, obliga imponer limitaciones que den cuenta de un justo y racional procedimiento. ${ }^{24}$

\section{EL DESPIDO POR INCUMPLIMIENTO DE LAS OBLIGACIONES LABORALES EN CHILE: ANÁLISIS DOCTRINARIO, LEGAL Y JURISPRUDENCIAL}

El término del contrato de trabajo por el incumplimiento de las obligaciones que impone el Contrato de Trabajo se encuentra regulado en nuestro país en el artículo $160 \mathrm{~N}^{\mathrm{o}} 7$ del C.T., ${ }^{25}$ teniendo sus antecedentes en las primeras leyes laborales, ${ }^{26}$ depurándose en el Código de $1931^{27}$ hasta nuestros días.

En Chile esta causal opera de manera bidireccional, ya sea cuando el término del contrato laboral encuentra su origen en la voluntad del empleador, como así también en la voluntad del trabajador por el incumplimiento de las obligaciones patronales, esta última posibilidad consagrada por expresa mención del artículo 171 del C.T., ${ }^{28}$ lo que ha permito afirmar por la doctrina ${ }^{29}$ -sin mucha rigurosidad técnica ${ }^{30}$ - que, por esta sola circunstancia, constituye el motivo más generalizado de terminación del contrato de trabajo en razón de su naturaleza bilateral.

${ }^{24}$ Ibíd.

${ }^{25}$ Art. $160 \mathrm{~N}^{\mathrm{o}} 7$ C.T.: "El contrato de trabajo termina sin derecho a indemnización alguna cuando el empleador le ponga término invocando una o más de las siguientes causales: (...) $\mathrm{N}^{\circ} 7$ Incumplimiento grave de las obligaciones que impone el contrato".

${ }^{26}$ Ley 4093 del Contrato de Trabajo, de 29 de septiembre de 1924, en su artículo 5º, indicaba que: “el contrato de trabajo termina con las causales jenerales de separación de los contratos, y, en especial por las siguientes: cuando una de las partes falta gravemente a sus obligaciones relativas a la ejecución del contrato" (sic).

${ }^{27}$ En su artículo 9 señalaba que: "el Contrato de Trabajo termina: $N^{\circ} 9$ por faltas graves a las obligaciones que impone el contrato de trabajo".

${ }^{28}$ V. Mella Cabrera, Patricio, "El despido indirecto o resolución del contrato de trabajo por incumplimiento patronal”, Revista de Derecho Universidad de Concepción, 2001, № 210 (Jul-Dic), pp. 95-102; Barahona Estay, Francisca, Despido Indirecto, Ed. Puntolex, Santiago, 2008.

${ }^{29}$ Nadal Serri, Daniel, El despido en el Código del Trabajo, Lexis Nexis, Santiago, 2003, p. 253. En similar sentido, Vargas Miranda, Rafael, Terminación del Contrato de Trabajo, Editorial Metropolitana, Santiago, 2014, T. II, p. 333.

${ }^{30}$ En la Encuesta Laboral (ENCLA) se ha indicado invariablemente en sus diversas versiones (2011, 2008, 2006, 2004, 2002, 1999 y 1998) que la causal de necesidades de la empresa (artículo 161 del C.T.) ha sido más utilizada que la causal de despido disciplinario (160 del C.T.), incluso incorporando a esta última los diversos motivos de despido imputables a la conducta del trabajador. 
En el contexto chileno se ha dicho que su explicación, en cuanto su naturaleza jurídica, descansa en que "la obligación de una de las partes es la obligación de la otra y violando un contratante cualquiera de las cláusulas del contrato, sean éstas expresas, tácitas o subentendidas, será causal suficiente para poner término al vínculo contractual". ${ }^{31}$ Esto último ha permitido entender su naturaleza jurídica desde la lógica civilista, particularmente desde la "condición resolutoria del contrato", pudiendo ser demandada la extinción por la parte diligente al no cumplirse por la contraria lo pactado. ${ }^{32}$

De igual forma se ha dicho que esta causal es subjetiva y voluntaria, "ya que guarda relación con hechos o faltas atribuibles a las partes o a la conducta de alguna de ellas, dando origen a un despido justificado, en el que si bien media un acto aparentemente unilateral de uno de los contratantes, tiene como fundamento la falta $u$ omisión de la otra parte, falta que autoriza para justificar el despido", ${ }^{33}$ entendiéndola como una expresión del poder disciplinario del empleador, en concreto como una sanción ${ }^{34}$ en el contexto de pena privada, ${ }^{35} \mathrm{a}$ propósito de sus funciones preventivas, tanto general como especial.

Ahora, más allá de las constataciones anteriores, debido a su amplia redacción y referencia a fuentes obligacionales diversas, se ha caracterizado como una hipótesis de despido con un contenido causal abierto, ${ }^{36}$ amplio, ${ }^{37}$ residual ${ }^{38}$ y genérico, ${ }^{39}$ que comprende situaciones fácticas que no encuentran un correlato en los supuestos habilitantes sustantivos de validez del artículo 160 del Código del Trabajo. Esto produce una absorción de motivos de

\footnotetext{
${ }^{31}$ Nadal Serri, cit. (n. 29), p. 253. En similar sentido, Vargas Miranda, cit. (n. 29), p. 333.

32 Thayer Arteaga, William; Novoa Fuenzalida, Patricio, Manual de Derecho del Trabajo, Editorial Jurídica de Chile, Santiago, 1980, T. III, p. 346.

${ }^{33}$ NAdAl SERri, cit. (n. 29), p. 256 y ss.

${ }^{34}$ Gamonal Contreras, Sergio; Guidi Moggia, Caterina, Manual del Contrato de Trabajo, Legal Publishing, Santiago, 2011, pp. 102, 277 y ss.

${ }^{35} \mathrm{~V}$. Fernández Toledo, cit. (n. 5).

${ }^{36}$ Melis Valencia, Cristián; Sáez Carlier, Felipe, El Contrato Individual de Trabajo en los Dictámenes de la Dirección del Trabajo, Editorial Jurídica Conosur, Santiago, 2009, p. 131.

${ }^{37}$ Gamonal y Guidi, cit. (n. 34), p. 279.

${ }^{38}$ Rojas MiÑo, Irene, Derecho del Trabajo. Derecho Individual del Trabajo, Thomson Reuters, Santiago, 2015, p. 425.

${ }^{39}$ Lizama Portal, Luis, Derecho del Trabajo, LexisNexis, Santiago, 2005, p. 182.
} 
despidos imperfectos, ${ }^{40-41}$ convirtiéndola en una causal de difícil delimitación, que termina por alejarse de los contornos fijados al poder disciplinario, desfigurando su finalidad como garantía frente a la arbitrariedad.

Estimamos que la caracterización doctrinaria y su utilización flexible, contraría la tipología causal que rige en materia de despido, por cuanto las causales disciplinarias tienen por finalidad delimitar hipótesis de incumplimientos graves y, producto de su particularidad, tipificarlas. Es por lo anterior que el artículo 160 del CT establece un catálogo específico que detalla los presupuestos infraccionales en que se subsume el comportamiento considerado como ilícito, así, el no cumplimiento de los requisitos que exige la ley para su advenimiento no logra configurar una causa justa de despido. Por lo anterior, el no poder subsumir un comportamiento en las causales de despido conlleva automáticamente que el despido no es la sanción proporcional y adecuada, ya que no existe en su tipología normativa la ponderación justificante, no teniendo por tanto la conducta la entidad sustancial para la extinción. ${ }^{42}$

Es por lo anterior que no podemos caracterizar la causal del despido por incumplimiento grave como una figura residual, en el sentido de ser sobrante, excedente o secundario del resto de las causales disciplinarias, ni tampoco como una figura genérica, esto es, una hipótesis causal común o base de despido, sino más bien como causa de contenido abierto e indeterminado de infracciones convencionales graves, que se delimitan por estándares de aplicación y ponderación. Lo anterior excluye la subsunción de hipótesis imperfectas del artículo 160 del Código del Trabajo en dicha causal. Constatando lo anterior y tratando de delimitar la causal en estudio, realizaremos un análisis de los requisitos que se han formulado por la doctrina y jurisprudencia para su operatividad, esto es, el incumplimiento de una obligación laboral de carácter grave y culpable.

\footnotetext{
${ }^{40}$ Lizama indica, en base a criterios jurisprudenciales, algunas hipótesis: los atrasos reiterados, estado de ebriedad, protesto de cheques, incumplimiento de metas de rendimiento. LizAMA PorTaL, cit. (n. 39), pp. 183-184. En similar sentido, reconociendo tal utilización, Melis Valencia y SaÉz Carlier, cit. (n. 36), pp. 132 ss.

${ }^{41}$ Según la Jurisprudencia configuran incumplimiento grave: la presentación al trabajo en estado de ebriedad (C.A. de Puerto Montt, 3 de noviembre de 2006, Rol 139-2006; C.S., 14 de octubre de 2002, Rol 2982-2002; C.A. de Santiago, 14 de enero de 2016, 1705-2015); realización de trabajos o negocios de la misma actividad comercial del empleador (C.A. de Santiago, 17 de julio de 2009, Rol 1780-2008); ausencias sistemáticas al trabajo (C.S., 13 de junio de 2013, Rol 1242-2013); atrasos en la presentación al trabajo (C.S., 11 de octubre de 2007, Rol 599-2007; C.A. de Punta Arenas, 1 de agosto de 2006, Rol 28-2006; C.A. de Santiago, 4 de julio de 2008, Rol 4534-2007), entre otros.

${ }^{42}$ En sentido similar, C.A. de Santiago, 30 de enero de 2013, Rol 1360-2012. No obstante, dicha resolución fue revocada por la C.S., en Sentencia de Unificación, de 13 de junio de 2013, Rol 1242-2013.
} 


\section{Incumplimiento de una obligación "laboral"}

\section{a) La pluralidad de las fuentes del contenido obligacional}

Desde sus orígenes, este motivo de despido ha tenido un alcance bastante amplio. La doctrina ha comprendido y extendido el contenido obligacional no sólo al contractual, sino que a otras fuentes normativas que impone al contrato. ${ }^{43}$ Vivanco señala que tal causal "no se refiere exclusivamente a las obligaciones pactadas en el contrato escrito, sino a las establecidas en las leyes y sus reglamentos, en el reglamento interno, y las sancionadas por los usos y costumbres. Comprende toda clase de instrucciones, órdenes y advertencias atinentes al trabajo encomendado". Agrega que "se refiere tanto a las conductas como al incumplimiento de las órdenes y advertencias impartidas por el empleador". ${ }^{4}$

En la misma línea, pero ampliando aún más su contenido, Nadal ha dicho que por las "obligaciones que impone el contrato de trabajo", no solo se debe entender "aquellas que emanen directamente del contrato mismo, sino aquellas cuyos efectos indirectos provienen del reglamento interno, de la ley misma incorporada al contrato o de un contrato colectivo, cuyos efectos son justamente la de reemplazar en lo pertinente a las contenidas en los contratos individuales de los trabajadores sujetos a negociación" . ${ }^{45-46-47}$ Agrega que, "en lo que respecta a la naturaleza de la obligación infringida ha de entenderse hecha a la relación de trabajo o contrato realidad y, por consiguiente, al conjunto de obligaciones y deberes que con ocasión de los servicios establece la ley, la voluntad de las partes y la propia naturaleza del vínculo". ${ }^{48}$ En el mismo sentido se ha reconocido que se incorporan al contenido contractual obligaciones emanadas de la costumbre o por la propia conducta de las partes. ${ }^{49}$

En razón de lo anterior, existe un cierto consenso para determinar el alcance de la causal, estando determinado por el contenido obligacional que

\footnotetext{
${ }^{43}$ Rojas MiÑo, cit. (n. 38), p. 425. Se fundamenta lo anterior en base a lo dispuesto en el artículo 1546 del Código Civil chileno.

${ }^{44}$ Vivanco Cisternas, Manuel, El Despido Laboral, Editorial Jurídica de Chile, Santiago, 1994, p. 81.

${ }^{45}$ NAdAl Serri, cit. (n. 29), p. 254.

${ }^{46}$ Sobre el punto, v. C.S., 5 de agosto de 2011, Rol 9407-2010, sentencia en la cual amplía el contenido obligacional al Contrato Colectivo y Buena Fe.

${ }^{47}$ En sentido contrario, Gamonal y Guidi, cit. (n. 34), p. 279.

${ }^{48}$ Ibíd.

${ }^{49}$ Lizama Portal, cit. (n. 39), p. 183.
} 
se haya estipulado por escrito (contenido expreso); las obligaciones o deberes de conducta que naturalmente se entienden incorporados (contenido ético del contrato de trabajo); y aquellas obligaciones que derivan de la dinámica fáctica de la relación de trabajo, que puedan configurar obligaciones no contenidas en el contrato escrito pero que se subentienden en razón de la prestación laboral concreta (cláusulas tácitas o subentendidas), ${ }^{50}$ todas las cuales pueden emanar de diversas fuentes normativas (contrato, ley, costumbre, reglamento interno, etc.) según lo ya indicado.

Nos llama la atención el amplio abanico de fuentes desplegado por la doctrina, cuando es la propia ley la que limita el contenido obligacional a aquellas de origen contractual. Es más, debemos constatar los riesgos de tal interpretación, ya que nos encontramos ante una hipótesis de despido disciplinario que, como máxima expresión del poder sancionatorio del empleador, debe someterse a criterios estrictos de "tipicidad", ${ }^{51}$ que se ven debilitados al introducir nociones vagas e imprecisas, de un alto grado de indeterminación, como lo son el contenido ético y deberes de conductas, y en menor medida las cláusulas tácitas o subentendidas. La introducción de nociones o conceptos jurídicos indeterminados en materia de causalidad del despido "generan inseguridad jurídica y desfavorece la posición de los más interesados en la plena justificación de las medidas extintivas como son los trabajadores". ${ }^{2}$

Creemos que un criterio delimitativo será que la sanción se extienda al incumplimiento de aquellas obligaciones de estricta fuente contractual o que tengan una conexión necesaria y directa con el contrato de trabajo, ${ }^{53}$ debiendo interpretarse sus cláusulas en correlación con las funciones que está obligado a desempeñar el trabajador. Ahora, en el evento de no estar escrituradas, se encontrasen indeterminadas o difusas (funciones y obligaciones), su interpretación deberá ser en contra del empleador por aplicación de los

\footnotetext{
${ }^{50}$ Sobre su reconocimiento en nuestro ordenamiento jurídico: C.S., 31 de marzo de 2004, Rol 10532003; C.A. de Concepción, 12 de noviembre de 2002, Rol 2.954-2002. Desde el punto de vista de los derechos del trabajador y la condición más beneficiosa como fuente de obligaciones y derechos tácitos o subentendidos, v. Ballester Laguna, Fernando, La condición más beneficiosa. Caracterización y eficacia de las mejoras contractuales, Comares, Granada, 2001, pp. 131 y ss.

${ }^{51}$ Fernández Toledo, cit. (n. 5), pp. 433 y ss.

52 Monereo Pérez, José L.; Fernández Avilés, José A., "La reconfiguración causal del despido colectivo: algunas reflexiones críticas", en Castiñeira Fernández, J. (Coord.), Presente y futuro de la regulación del despido, Aranzadi, Madrid, 1997, p. 172.

${ }^{53}$ En este sentido, C.A. de Concepción, 5 de abril de 2011, Rol 355-2010. "El incumplimiento, entonces, debe tener una conexión necesaria y directa con el contrato de trabajo. Ello impide extender la sanción a cualquiera otra fuente, privilegiando la de carácter contractual, y que corresponde a aquella que cae directamente bajo los sentidos de los contratantes".
} 
artículos 1563, 1564 y 1566 del Código Civil. De otro modo se generará una imprecisión adicional a la vaguedad de esta causal ${ }^{54}$ que beneficia a quien detenta una posición de superioridad, máxime si es la propia ley laboral que obliga la escrituración y claridad del contenido obligacional y funciones de la prestación laboral, ${ }^{55}$ siendo exigible, por los mismos fundamentos, claridad en el seno del régimen obligacional y sancionatorio.

\section{b) El reglamento interno: ¿hipótesis de incumplimiento que justifica el despido?}

Por la doctrina se ha dicho expresamente "que el reglamento interno no puede estatuir obligaciones a este respecto, porque emana de la voluntad unilateral del empleador". ${ }^{56}$ En la misma línea, pero de forma un tanto matizada, se ha sostenido que la transgresión por parte del trabajador de una prohibición establecida en el reglamento interno, sólo acarrea a éste la aplicación de las sanciones propias del reglamento interno previstas en el artículo $154 \mathrm{~N}^{\circ}$ 10 en relación con el artículo 157, ambos del C.T., siendo solo posible la amonestación o multa, pero no tendrá la posibilidad de generar el término del contrato de trabajo, a menos que expresamente se contractualice. ${ }^{57}$

No obstante, la jurisprudencia judicial ${ }^{58} \mathrm{y}$ la doctrina mayoritaria ${ }^{59}$ ha tenido una postura distinta, afirmando que el trabajador que infringe la normativa del reglamento interno incurre en incumplimiento grave de las obligaciones, manifestando, no obstante, que la gravedad ha de ser calificada por los tribunales de justicia.

\footnotetext{
${ }^{54}$ En un similar sentido se ha resuelto que "para establecer si el demandante incumplió gravemente las obligaciones que le impone su contrato de trabajo, resulta básico tener certeza acerca de la exacta naturaleza de los servicios que debía prestar para su empleador". En dicho fallo se indica que no cumple esta exigencia el contrato que no contiene la descripción del cargo ni señala las tareas que debe cumplir el trabajador. C.A. de Santiago, 3 de septiembre 2002, Rol 7069-2001.

${ }_{55}^{55}$ Como se desprende de una interpretación armónica y teleológica de los artículos 9, 10 y 154 del C.T.

${ }^{56}$ Gamonal y Guidi, cit. (n. 34), p. 279.

${ }^{57}$ Dirección del Trabajo, Dictamen ord. N ${ }^{\circ} 766 / 317,21$ de noviembre de 1995. Citado por VARGAS Miranda, cit. (n. 29), I, p. 393. Reconociendo dicha posibilidad: C.A. de Concepción, 5 de diciembre de 2007, Rol 594-2007.

${ }_{58}$ C.S., 23 de abril de 1992, Rol 5699; C.A. de Concepción, 30 de enero de 2009, Rol 438-2008; C.A. de Santiago, Rol 853-1999, citados por Vargas Miranda, R., cit. (n. 29), I, p. 393 y ss.; C.A. de Antofagasta, 12 de octubre de 2005, Rol 159-2003. En sentido contrario, C.A. de Concepción, 5 de diciembre de 2007, Rol 594-2007.

${ }^{59}$ En esta línea, Nadal Serri, cit. (n. 29), Vivanco Cisternas, cit. (n. 44), Vargas Miranda, cit. (n. 29), THAYER y NOVOA, cit. (n. 32).
} 


\section{c) El contenido ético y los deberes de conducta}

Para un sector de la doctrina esta causal de término puede justificarse en el incumplimiento de aquellas obligaciones que emanan del contenido ético del contrato de trabajo, esto es aquellas que naturalmente se entienden incorporadas a él, que no se señalan expresamente y que emanan principalmente de los deberes de conducta. Sobre el punto la doctrina laboral entiende que "el contenido ético jurídico no es sino el conjunto de derechos y obligaciones correlativas que regulan la relación entre trabajador y empleador, con el objeto de proteger ciertos bienes jurídicos de carácter ético, tales como la vida y el respeto recíproco", ${ }^{60}$ el cual está compuesto por a) deber de respeto; b) deber de cuidado; c) deber de diligencia; d) deber de fidelidad; e) deber de probidad, los que justifican su existencia jurídica en el "artículo 1546 del Código Civil, en cuanto prescribe que los contratos deben ejecutarse de buena fe, y por consiguiente obligan no solo a lo que en ellos se expresa, sino a todas las cosas que emanan precisamente de la naturaleza de la obligación, o que por la ley o la costumbre pertenecen a ella", ${ }^{61}$ cuestión que ha sido del todo validada por la jurisprudencia, tanto para la creación de obligaciones como para la justificación de incumplimientos de las mismas. ${ }^{62}$

En esta línea, se han reconocido la existencia de "deberes de conducta" que refieren a "comportamientos impuestos, ínsitos del contrato de trabajo -propiamente, elementos de su esencia- que tienen una connotación ética, introduciendo pautas axiológicas a su contenido obligacional propiamente patrimonial", las cuales se denominan "obligaciones de solidaridad y colaboración" o "deberes de corrección social", los que suponen que ninguna de las partes del contrato ha de incurrir en comportamientos determinados, en detrimento de la otra, con fundamento en la necesidad de posibilitar la pacífica coexistencia, procurando un uso amplio y provechoso de la regla de la buena fe,

\footnotetext{
${ }^{60}$ Ugarte Cataldo, José L., "El contenido del Contrato individual de Trabajo", Boletín Oficial de la Dirección del Trabajo, 1996, No 94 (nov.), p. 18.

${ }^{61}$ Thayer y Novoa, cit. (n. 32), III, p. 336, cita 185.

${ }^{62}$ C.A. de Concepción, 12 de noviembre de 2002, Rol 2954-2002. En similar sentido, C.S., 31 de marzo 2004, Rol 1053-2003; C.A. de Santiago, 11 de enero de 2005, Rol 1861-2003; C.S., 5 de agosto de 2011, Rol 9407-2010; C.A. de Rancagua, 3 de diciembre de 2001, Rol 3713-2001; C.A. de Concepción, 3 de marzo de 2006, Rol 3350-2005; C.A. de Santiago, 29 de octubre 2004, Rol 8.624-2004; C.A. de Concepción, 3 de marzo de 2006, Rol N 3.350-2005; C.A. de Iquique, 03 de septiembre de 2007, Rol 69-2007; C.S., 13 de mayo de 2008, Rol 1003-2008; C.S., 4 de diciembre de 2008, Rol 6.072-2008; C.S., 13 de junio de 2013, Rol 1242-2013; C.A. de La Serena, 7 de noviembre de 2013, Rol 119-2013; C.A. de Santiago, 14 de noviembre de 2014, Rol 610-2014; C.A. de Santiago, 24 de noviembre de 2014, Rol 1276-2014.
} 
y tendiendo a precaver el riesgo de que la actividad o negligencia de un sujeto provoque perjuicios en la otra. Se agrega que "tal contenido obligacional ético a que se viene aludiendo, está llamado a ejercer una importante función normativa en el ámbito de las relaciones laborales, determinando, por una parte, la conducta que deben asumir los sujetos contratantes durante el desenvolvimiento de su vinculación y, por otra, la sujeción a múltiples deberes éticos, entre los cuales resulta pertinente aludir, en la situación de autos, al 'deber de diligencia y rendimiento' impuesto al trabajador, que ha sido conceptualizado como una forma de colaboración que éste se encuentra obligado a prestar para la buena marcha de la empresa a que está vinculado, "que se concreta en la obligación de dar en su trabajo el rendimiento propio o normal del buen trabajador, atendidas las funciones para que ha sido contratado". ${ }^{63}$

El problema de tal configuración doctrinaria, reconocida pacíficamente por la doctrina y jurisprudencia -más allá de las críticas ideológicas y aprensiones teóricas que puedan realizarse a las ideas comunitarias que la sustentan-64 es que produce negativas consecuencias para el trabajador, por cuanto su contenido queda indeterminado, pudiendo calificarse como incumplimientos de obligaciones aquellas que el trabajador no tenía conocimiento, sirviendo para encubrir hipótesis ficticias, todo de una manera imprecisa y que, bajo el influjo de tales planteamientos, genera una fuerte dependencia del trabajador más allá de la prestación obligacional patrimonial contractual.

Esto último, se acrecienta cuando observamos una verdadera asunción de "códigos éticos" y "manuales de conductas" que establecen comportamiento y compromisos concordantes a valores corporativos ${ }^{65}$ que mediante la noción del deber de obediencia, fidelidad, lealtad y deberes de conducta, podrían ingresar indirectamente al contrato de trabajo como un contenido obligacional derivado del contenido ético y el poder empresarial, debilitando la protección que pretende la regulación del despido.

Debemos recalcar aquí la crítica a tal supuesto, ya que de manera innegable dichas ideas han producido una "sobrecarga de deberes", "vigorizando y ampliando las posibilidades de resolución del contrato por incumplimiento"

\footnotetext{
${ }^{63}$ C.A. de Concepción, 06 de septiembre de 2002, Rol 4082-2001.

${ }^{64}$ V. Domínguez Montoya, Álvaro, "Análisis crítico al Derecho del Trabajo: entre el paternalismo y la emancipación", Revista de Estudios Ius Novum, 2012, № 5, pp. 45 y ss.; MarTín VALVERDE, Antonio, "Ideologías jurídicas y contrato de trabajo", en AA.VV., Ideología y relaciones de trabajo, Publicaciones Universidad de Sevilla, Sevilla, 1978.

${ }^{65}$ V. Calvo Gallego, Francisco, Códigos Éticos y Derechos de los Trabajadores. Una aproximación a la práctica en las empresas españolas, Bomarzo, Albacete, 2008.
} 
que no hace más que extender la posibilidad de una resolución fundada en el mismo. ${ }^{66}$ Como indicó en su oportunidad Alonso Olea, "caminar en otro sentido es, volver a resucitar tesis, que parecen definitivamente superadas, sobre el posible origen no contractual de la relación de trabajo", ${ }^{67}$ volviendo a la fundamentación comunitaria o relacionista, subordinando al trabajador, en términos de fidelidad y lealtad, al señorío e intereses del nuevo señor feudal. ${ }^{68}$

En esta línea crítica creemos que el contenido obligacional a que se refiere la causal legal en estudio, es sólo el contractualizado de manera expresa (el contrato y la ley) o de manera tácita (por la función laboral propia que desempeña el trabajador) en correlación a las obligaciones estipuladas, excluyendo los deberes de conducta identificados clásicamente con la lealtad, fidelidad y obediencia impuestos por el contenido ético del contrato de trabajo.

\section{El incumplimiento contractual debe ser grave}

\section{a) La gravedad y algunos criterios jurisprudenciales para su ponderación}

Se exige normativamente como elemento determinante en aplicación de dicha causal de despido la "gravedad" del incumplimiento que se invoca. No obstante, el legislador no ha formulado un concepto legal, siendo la jurisprudencia quien se ha encargado de fijar los criterios delimitadores. En términos muy concretos, la gravedad del incumplimiento se pondera en base a la magnitud, volumen, entidad o importancia del incumplimiento en correlación con la posibilidad o imposibilidad de hacer posible la continuidad de la relación laboral, siendo el despido la única respuesta posible en cuanto sanción. Lo anterior determina que el incumplimiento debe estar identificado claramente con la medida adoptada y que pueda ser probado, como así también, vinculado estrictamente al contrato de trabajo. ${ }^{69}$

Es así que podemos observar una pluralidad de criterios jurisprudenciales

para la calificación de la intensidad del incumplimiento, los cuales pueden resumirse en el carácter aislado de la situación ${ }^{70}$ si ésta afecta el funcionamiento

\footnotetext{
${ }^{66}$ Alonso Olea, cit. (n. 2), pp. 122 y 123.

${ }^{67}$ Ibíd., pp. 120 y ss.

${ }^{68}$ Domínguez Montoya, “Análisis crítico...”, cit. (n. 64), p. 47.

${ }^{69}$ V. GonZÁlez-Posada MarTínez, Elías, "La noción de incumplimiento contractual grave y culpable en la Jurisprudencia”, en Gil y Gil, J.; Manuel del Valle, J. (Coords.), El despido disciplinario: Homenaje al Profesor Juan Antonio Sagardoy Bengoechea, Cinca, Madrid, 2009, p. 113.

${ }^{70}$ C.A. de Valdivia, 26 de agosto de 2008, Rol 70-2008. En similar sentido C.A. de Santiago, 31 de julio
} 
y estabilidad de la empresa, ${ }^{71}$ si genera un perjuicio económico, ${ }^{72}$ la cantidad de años que el trabajador lleva prestando servicios para el empleador, ${ }^{73}$ los antecedentes laborales del trabajador, ${ }^{74}$ la gradualidad de la sanción (correspondencia entre la falta y su sanción), ${ }^{75}$ la conducta anterior del trabajador ${ }^{76}$ las funciones y responsabilidad del cargo, ${ }^{77}$ entre otros. ${ }^{78}$

Se ha resuelto por la Jurisprudencia de manera uniforme que el incumplimiento debe ser de una magnitud o entidad tal que determine necesariamente el quiebre de la relación laboral, que afecte en esencia el acatamiento de las obligaciones de una de las partes. ${ }^{79}$ Esto se vincula con el desempeño del trabajador y el contexto de la relación del trabajo, de la situación del trabajador en la empresa, el cargo y naturaleza de las funciones que desempeñaba, y la mayor o menor responsabilidad en la imputación formulada. ${ }^{80}$

De igual forma se considera como criterio la conducta del trabajador, en cuanto hechos aislados o repetitivos, en relación a las labores propias del cargo. ${ }^{81}$

En este esquema se ha exigido que la falta disciplinaria afecte sensiblemente el funcionamiento de la empresa en que se trabaja, ${ }^{82}$ que sea

de 2002, Rol 5.072-2001. Asimismo, C.S., 30 de enero de 2006, Rol 2703-2005; C.A. de Antofagasta, 30 de abril de 2009, Rol 40-2009; C.A. de Concepción, 4 de octubre de 2007, Rol 298-2007.

${ }^{71}$ C.A. de San Miguel, 8 de junio de 2004, Rol No 34-2004. En similar sentido, C.S., 13 de agosto de 2002, Rol 1734-2002.

${ }^{72}$ C.S., 13 de agosto de 2002, Rol 1734-2002; C.A. de Concepción, 6 de septiembre de 2002, Rol N ${ }^{\circ}$ 4.082-2001; C.A. Concepción, 12 de noviembre de 2003, Rol 2954-2002; C.A. de Santiago, 15 de julio de 2014, Rol 195-2014.

${ }^{73}$ C.S., 29 de enero de 2007, Rol 2.498-2005.

${ }^{74}$ C.A. de Rancagua, noviembre de 2011, Gaceta Jurídica No 281 (2003), pp. 172 ss.; C.A. de Santiago, 3 de septiembre de 2002, Rol 7.069-2001. En el mismo sentido, C.A. de Concepción, noviembre de 2002, Gaceta Jurídica No 269 (2002), p. 186.

${ }^{75}$ C.A. de Santiago, 02 de junio de 2006, Rol 6329-2005.

${ }^{76}$ C.A. de Valdivia, 26 de agosto de 2008, Rol 70-2008.

${ }^{77}$ C.A. de Santiago, 11 de abril de 2007, Rol 3754-2007.

${ }^{78}$ C.S., 13 de agosto de 2002, Rol 1734-2002.

${ }^{79}$ Sentencia que puede encontrarse en Gaceta Jurídica N ${ }^{\circ}$ 40, 1983 (oct.), p. 113, citada por ITURRA TAPIA, María Rosa, "Aspectos laborales relacionados con el cheque con especial mención a la terminación del contrato de trabajadores bancarios, motivado en protestos de cheques personales", memoria de prueba de pregrado, Universidad de Chile, Santiago, 2007, disponible en línea: www.tesis.uchile.cl/ tesis/uchile/2007/iturra_m/sources/TESIS_Iturra_m.doc; C.A. de Valparaíso, enero de 2000, Gaceta Jurídica $\mathrm{N}^{\mathrm{o}} 262$ (2002), p. 169. En similar sentido, C.A. de Antofagasta, 30 de abril de 2009, Rol $\mathrm{N}^{\circ}$ 40-2009; C.S., 30 de julio de 2008, Rol 2164-2008; C.S., 21 de octubre de 2008, Rol 5087-2008.

${ }^{80}$ C.A. de San Miguel, 2 de noviembre de 2004, Rol N 4.377-2003.

${ }^{81}$ C.S., 30 de enero de 2006, Rol 2703-2005.

${ }^{82}$ C.A. de San Miguel, 08 de junio de 2004, Rol 34-2004. 
reiterada y que causa perjuicio al empleador, ${ }^{83}$ debiendo necesariamente acreditarse el mismo, no siendo suficiente para justificar la terminación de la relación laboral cualquier falta a los deberes contractuales. ${ }^{84}$

De igual forma y en el contexto anterior, ha de considerarse al momento de interpretar la procedencia y gravedad que necesariamente la única sanción posible frente al incumplimiento contractual sea el despido y no otra de menor intensidad. ${ }^{85}$ Esto, porque el incumplimiento debe tener la magnitud de generar el quiebre en la relación laboral suficientemente grave para justificar un despido,${ }^{86}$ en atención a que se priva al trabajador del derecho a indemnización ${ }^{87}$ y que en hipótesis de ilegalidad, conlleva una mayor indemnización. ${ }^{88}$

\section{b) La Gravedad y autonomía de las partes}

Una de las principales observaciones que se han realizado por la doctrina en la caracterización del despido disciplinario, es la vigencia del "principio de indisponibilidad tipológica", esto es, que las causas justas de despido solo pueden ser establecidas por el legislador y no por las partes. ${ }^{89}$

Esta circunstancia determina que la calificación de gravedad de los incumplimientos contractuales se resuelva por tribunales de justicia, ya que, de otro modo se estaría autorizando a las partes y en particular al empleador, a establecer motivos causales de terminación del contrato.

En la jurisprudencia se ha discutido la posibilidad que las partes de común acuerdo (contrato de trabajo) o unilateralmente (reglamento interno) califiquen a priori la gravedad de un incumplimiento de determinadas obligaciones.

Una de estas interpretaciones entiende que las partes en razón de la autonomía de la voluntad pueden precisar por vía contractual cuando un incumplimiento tiene la gravedad suficiente para justificar la causal del despido en estudio. ${ }^{90}$ En esta línea se ha resuelto que desconocer lo expresamente pactado por las partes, conllevaría el desconocer los términos estipulados por

\footnotetext{
${ }^{83}$ C.A. de La Serena, 25 de agosto de 2010, Rol 82-2010.

${ }^{84}$ C.S., 17 de noviembre de 2008, Rol 5635-2008.

${ }^{85}$ Walker Errázuriz, Francisco, Terminación del contrato de trabajo, Cepet, Santiago, 1990, pp. 52-53.

${ }^{86}$ C.S., 4 de diciembre de 2008, Rol 6072-2008.

${ }^{87}$ C.S., 14 de enero de 2008, Rol 6151-2007.

${ }^{88}$ C.A. de San Miguel, 18 de abril de 2013, Rol 92-2013.

${ }^{89}$ Gamonal y Guidi, cit. (n. 34), p. 277.

${ }^{90}$ C.S., 14 de abril de 1993, Rol 7.966, citada por ItURRA TAPIA, cit. (n. 79), p. 41.
} 
escrito, omitiendo la clara y manifiesta intención que los contratantes tuvieron al celebrar libre y espontáneamente el contrato. ${ }^{91}$

La tesis mayoritaria indica que no corresponde que, por la vía de la estipulación contractual, se pretenda calificar a priori cualquier incumplimiento como constitutivo de una infracción grave a las obligaciones que impone el contrato, porque tal calificación compete exclusivamente a los tribunales de justicia en función de los hechos efectivamente acreditados en el curso del proceso. $^{92}$

Resulta determinante para la jurisprudencia el hecho que el vínculo de trabajo sea considerado como un contrato de adhesión ${ }^{93}$ como así también el principio de irrenunciabilidad de derechos, ${ }^{94}$ en la medida que aceptar la posibilidad de calificar el incumplimiento laboral grave sin una ponderación judicial, conllevaría que quien detenta el poder dentro de la relación laboral fije unilateralmente el contenido de su propio poder disciplinario. Incluso dicha posibilidad puede significar infracción de los artículos 160 y 5 del C.T. porque involucra ampliar el campo de las causales de terminación del contrato de trabajo ${ }^{95}$ más allá de los propios términos de tipología causal establecida por el legislador.

Este criterio ha sido compartido por la Dirección del Trabajo, quien ha resuelto reiteradamente que no existe inconveniente jurídico para que el empleador describa conductas que signifiquen, a su juicio, causales de término o caducidad del contrato de trabajo. No obstante, la determinación de si ellas encuadran o no en las causales previstas por la ley compete, en definitiva, a los Tribunales de Justicia. ${ }^{96}$

\footnotetext{
${ }^{91}$ Sentencia en Manual de Consultas Laborales y Previsionales No 193, 1997 (abr.), pp. 331 y ss.; citada por ItURRA TAPIA, cit. (n. 79), p. 41.

92 Entre muchas otras: C.A. de Concepción, Rol 3497-9; ItURRa TAPIA, cit. (n. 79); C.A. de Santiago, 15 de septiembre de 2000, Rol 1295-2000; C.A. de Santiago, 11 de octubre de 2002, Rol 6.660-2001; C.A. de Santiago, 11 de diciembre de 2002, Rol 6660-2002; C.A. de Santiago, 10 de enero de 2006, Rol 23632005.

${ }^{93}$ C.S., 30 de enero de 1995, Rol 6053; citada en Ord. Dirección del Trabajo, N N 1753/40. En similar sentido C.S., 3 de septiembre de 2002, Rol N 2.705-2002; C.A. de Concepción, 17 de octubre de 2005, Rol N².198-2005.

${ }^{94}$ C.S., 17 de abril de 2000, Rol No 2449-1999; C.S., 31 de mayo de 2001, Rol 866-2001.

${ }_{95}^{5}$ En un sentido similar, C.A. de Concepción, 15 de septiembre, Rol 1295-2000; C.S., 30 de enero de 2006, Rol 2703-2005.

${ }^{96}$ Dirección del Trabajo, Ord. № 1851/0085, 22 de mayo del 2001; Ord. № 1753/40, 5 de mayo de 2003; en idéntico sentido, C.A. de Arica, 15 de septiembre de 2008, Rol N 94-2008.
} 


\section{c) La gravedad y su impugnación mediante recursos de derecho}

Una cuestión debatida respecto del control judicial de dicha causal y su eventual impugnación, ha sido la de cuestionar ante tribunales superiores de justicia -mediante recursos de derecho como el Recurso de Nulidad- ${ }^{97}$ la calificación del despido por indebida o correcta aplicación del artículo 160 $\mathrm{N}^{\mathrm{o}} 7$ del C.T., teniendo en cuenta si la gravedad del incumplimiento de la obligación es una cuestión de hecho o derecho.

Al respecto se ha dicho que la calificación "es una cuestión de hecho, cuya determinación queda entregada al prudente arbitrio judicial". ${ }^{98}$ En tal sentido la Excma. Corte Suprema ha indicado en reiteradas oportunidades que, debido a tal circunstancia, es imposible controlar su calificación mediante recursos que no tienen el alcance de control y discusión de prueba, como también la valoración de la misma. Se ha resuelto que "lo pretendido es en definitiva, alterar los hechos asentados, modificación que no es posible por esta vía”, siendo el establecimiento de los hechos una cuestión que "corresponde a una facultad propia de aquellos jueces y no permite revisión por este medio, salvo que para concluir en determinado sentido se hayan transgredido las normas científicas, de la experiencia, técnicas o simplemente lógicas". ${ }^{99}$ En similar sentido se ha dicho que “ (...) debe precisarse que el recurrente se limita a contrariar los hechos establecidos en el fallo atacado e intenta modificarlos (...) Tal reproche no es susceptible de revisión por esta vía, según lo ha decidido reiteradamente este tribunal, salvo que en la fijación de los hechos se hayan quebrantado las leyes reguladoras de la prueba, lo que no se advierte del mérito del proceso, ni ha sido denunciado en tales términos por el recurrente". ${ }^{100-101}$

En esta variante existen diversos pronunciamientos que han entendido que la calificación del despido motivado por el incumplimiento grave de las obligaciones del contrato de trabajo es una materia susceptible de ser controlada

\footnotetext{
${ }^{97}$ V. sobre la caracterización de tal recurso: Domínguez Montoya, Álvaro; Mella Cabrera, Patricio, "El Recurso de Nulidad Laboral", Revista de Derecho Universidad de Concepción 2011, No 229-230 (Ene-Dic.), pp. 121-170.

98 Thayer y Novoa, cit. (n. 32), IV, p. 59.

${ }^{99}$ C.S., 14 de enero de 2008, Rol 6151-2007. En similar sentido, pero en relación con el art. 478 letra c) del C.T., C.A. de Temuco, 11 de junio de 2015, Rol 72-2015.

100 C.S., 13 de mayo de 2009, Rol 1003-2008.

101 En esta línea jurisprudencial: C.S., 18 de noviembre de 2003, Rol 3841-2003; C.S., 9 de abril de 2006, Rol 5192-2005; C.S., 28 de abril de 2005, Rol 5409-2004; C.S., 04 de diciembre de 2008, Rol 5593-2008; C.S., 31 de diciembre de 2008, Rol 7137-2008; C.S., 23 de septiembre de 2011, Rol 6622011.
} 
mediante recursos de derecho por infracción a las reglas de la Sana Crítica ${ }^{102}$ o derechamente aplicando un control de ponderación de pruebas sobre la misma. ${ }^{103}$ Actualmente tal posibilidad se da mediante la vía impugnativa del Recurso de Nulidad Laboral, permitiéndose su control por la causal del artículo 478 letra b) de nuestro C.T., lo que ha llevado al tribunal de nulidad el establecer la ponderación de la gravedad en su respectiva sentencia de reemplazo. ${ }^{104}$

A nuestro entender, la cuestión es del todo compleja, por cuanto el sistema de recursos impugnativos en el ordenamiento procesal laboral se sostiene en los principios de inmediación y oralidad, que constituyen barreras insalvables para los efectos de que el tribunal de nulidad pueda directamente alterar los hechos y en estricto rigor, realizar una nueva valoración de la prueba, a lo que debe agregarse la dificultad de determinar con exactitud el límite entre los hechos y el derecho.

Atendiendo las complejidades anteriores, creemos que dependerá de qué forma concurre el vicio de nulidad y la causal concurrente, lo que se diferenciará por la ponderación judicial de la totalidad o parcialidad de la prueba rendida.

En el caso que el sentenciador no hubiese valorado la totalidad de la prueba rendida, esto es, cuando no hubiese ponderado los antecedentes probatorios que digan cuenta a criterios de determinación de la magnitud, volumen, entidad o importancia de la gravedad del incumplimiento, ${ }^{105}$ se configuraría un vicio que permitiría anular la sentencia por infracción al sistema de valoración de la prueba, por cuanto, como bien lo ha resuelto la jurisprudencia, él no realiza una valoración de todos los medios aportados por las partes, como tampoco realiza una valoración integral de las pruebas, limitándose a extractar sólo aspectos parciales de los mismos, configuraría una hipótesis subsumible en la causal del 478 letra b) del C.T., ${ }^{106}$ puesto que la apreciación conforme a la sana crítica

102 C.S., 13 de agosto de 2002, Rol 1734-2002; C.A. de Puerto Montt, 17 de octubre de 2005, Rol 40-2005. C.S., 9 de marzo de 1999, Rol 3612-1997; C.S., 9 de abril de 1991, Rol 3583-1991; C.S., 4 de diciembre de 2008; Rol 6072-2008.

103 C.S., 30 de octubre de 2006, Rol 2291- 2005.

104 C.A. de Santiago, 30 de mayo de 2014, Rol 1783-2013; C.A. de Concepción, 12 de diciembre de 2014, Rol 326-2014; C.A. de Santiago, 15 de enero de 2015, Rol 1256-2014; C.A. de Chillán, 11 de febrero de 2014, Rol 6-2014.

${ }^{105}$ Carácter aislado de la situación, afectación del funcionamiento y estabilidad de la empresa, perjuicio económico, la cantidad de años que el trabajador lleva prestando servicios para el empleador, los antecedentes laborales del trabajador, correspondencia entre la falta y su sanción, la conducta anterior del trabajador.

106 C.A. de La Serena, 03 de agosto de 2009, Rol 75-2009; C.A. de Valparaíso, 20 de enero 2010, Rol 569-2009; C.A. de Santiago, 20 de enero de 2010, Rol 70-2009; Sentencia C.A. de Concepción, 02 de septiembre de 2010, Rol 214-2010; Sentencia C.A. de Antofagasta, 19 de abril de 2010, Rol 58-2009; Sentencia C.A. de San Miguel, 16 de abril de 2010, Rol 1-2010. 
"conlleva el deber de analizar y evaluar todos los elementos de convicción que se aportan para solucionar el pleito". ${ }^{107}$ De igual forma podría plantearse, sin cuestionar los hechos y de manera independiente, la causal 478 letra e) del C.T., en la medida que se omiten medios de pruebas determinantes que influyan sustancialmente en lo dispositivo del fallo. Ahora, si efectivamente se ha ponderado la totalidad de la prueba rendida y se deduzca lógicamente la conclusión que convence al sentenciador, la causal deberá enfocarse a la calificación jurídica de los hechos, esto es al artículo 478 letra c) del C.T. y no a cuestionar la ponderación propiamente tal en cuanto al establecimiento de los hechos. ${ }^{108}$

Justificamos lo anterior en atención a que la calificación es una cuestión relativa a la asignación de un acto a una categoría jurídica, que conlleva identificar la naturaleza de los hechos probados, definir su esencia y propiedades características o bien la concreción de conceptos y estándares indeterminados. El "perímetro específico" de la causal busca "la impugnación de aspectos valorativos" cuando las precisiones de elementos normativos no se agoten en la comprobación de hechos ni el mero contraste de éstos con los enunciados de la norma, ${ }^{109}$ que es precisamente la actividad que conlleva la calificación de gravedad del incumplimiento, la que por lo demás, no es un hecho sino un grado de apreciación que recae sobre una experiencia constitutiva de un juicio de valor. ${ }^{110}$

\section{El incumpliendo debe ser culpable}

Una interrogante que se formula sobre la causal en análisis, es la posibilidad de exigir que el incumplimiento además de grave sea culpable. Si bien no ha existido claridad jurisprudencial sobre el punto, ${ }^{111}$ desde un punto de vista dogmático y partiendo de la base que el motivo de despido tiene una naturaleza disciplinaria, exige "una conexión entre la voluntad de aquel y

107 C.A. de Valdivia, 14 de enero de 2010, Rol 88-2009.

${ }_{108}$ En un sentido similar, C.A. de Chillán, 1 de abril de 2013.

${ }^{109}$ Astudillo Contreras, Omar, El recurso de Nulidad Laboral. Algunas consideraciones técnicas, Thomson Reuters, Santiago, 2012, pp. 129-138; en especial pp.134-138.

${ }_{110}$ V. fundamento $3^{\circ}$ de sentencia de C.A. de Santiago, 5 de abril de 2011, Rol 1590-2010, citada por Astudillo Contreras, cit. (n. 109), pp. 136 y ss. En similar sentido, pero en otros términos, C.A. de Antofagasta, 15 de enero de 2014, Rol 167-2013.

111 C.A. de La Serena, 25 agosto de 2010, Rol 82-2010. En sentido contrario, C.A. de Iquique, 3 de septiembre de 2007, Rol N 69-2007. 
el hecho que da lugar a la sanción", ${ }^{112}$ que solo puede ser imputable a una conducta culpable que se expresa mediante el dolo o culpa.

En efecto, la culpabilidad caracteriza de manera terminante no sólo las causas generales del despido disciplinario, sino que va más allá y se extiende a toda causa y sanción disciplinaria del empleador. Incluso, si nos situamos en la fundamentación civilista del despido como resolución del contrato de trabajo, el incumplimiento debe ser necesariamente culpable, por cuanto el despido disciplinario en sí es subjetivo y atiende a la conducta del trabajador, pudiendo incluso haber causales de justificación exculpatoria por aplicación directa de la dogmática del derecho de los contratos. Entenderlo de otro modo impediría el control judicial de aspectos subjetivos propios de la configuración de la causa. Por lo anterior no se observa en qué medida debería excluirse como requisito copulativo para su concurrencia.

A propósito de la exigencia de culpabilidad, la doctrina ha señalado que el incumplimiento debe ser producto del dolo o culpa grave del trabajador, incluyendo causales de justificación del incumplimiento. ${ }^{113}$

Estimamos que tal requisito se extiende a la posibilidad que la acción objeto de reproche no deba encontrar justificación, por no ser exigible objetiva y racionalmente otra conducta al concurrir circunstancias peligrosas o razones poderosas que justifiquen el incumplimiento, posibilitándose el no cumplimiento deliberado de una obligación de forma justificada. ${ }^{114}$

Esta posición encuentra fundamentación en base a lo que la doctrina ha denominado "derecho a la resistencia", "derecho a la desobediencia legítima" o ius resistentiae, que nace como excepción al principio solve et repete contextualizado a la oposición justificada de una orden ${ }^{115}$, enmarcado en la doctrina de la obediencia justa. ${ }^{116}$ Este derecho se extiende no solo a las órdenes e instrucciones, sino también a todo el espectro de la relación laboral

112 Aguilera IzQuierdo, Raquel, Las causas del despido disciplinario y su valoración por la Jurisprudencia, Aranzadi Editorial, Madrid, 1997, pp. 47 y ss.

113 Gamonal y Guidi, cit. (n. 34), p. 279.

114 Vid. GonzÁlez-Posada Martínez, cit. (n. 69), p. 118.

115 Contextualizando tales nociones y conceptos en el despido, V. Aguilera IzQuierdo, cit. (n. 112), Capítulo II, "Causas de despido disciplinario relativas al deber de disciplina en el trabajo o deberes conexos al mismo"; Guerrero Ostolaza, José M., "La desobediencia e indisciplina en el trabajo", en Gil y Gil, J.; Manuel del Valle, J. (Coords.), El despido disciplinario: Homenaje al Profesor Juan Antonio Sagardoy Bengoechea, Cinca, Madrid, 2009, pp. 127-145.

116 Montoya Melgar, Alfredo, "Dirección y Control de la actividad laboral”, en Borrajo Dacruz, Efrén (director), Comentarios a las leyes laborales. El estatuto de los trabajadores, Ed. Edersa, Madrid, 1985, T. V, p. 138. 
como una forma de defensa de los intereses legítimos y derechos propios del trabajador, alcanzando a la exigencia del cumplimiento de las obligaciones que impone el contrato de trabajo.

\section{OPORTUNIDAD, FORMALIDADES, IMPUGNACIÓN Y REPARACIÓN}

\section{Oportunidad}

Respecto de la oportunidad del despido por el incumplimiento grave de las obligaciones que impone el contrato rige el principio de inmediatez en la materialización de la sanción disciplinaria, ${ }^{117}$ debiendo ser la extinción efectuada en un breve y determinado período. ${ }^{118}$

En el contexto chileno, si bien su configuración posee un carácter normativo, ${ }^{119}$ la ley laboral "en una grave omisión" ${ }^{120}$ no ha establecido un plazo para su ejercicio, siendo la jurisprudencia quien ha introducido la noción de "perdón de la causal" o "condonación de la falta" para delimitar la temporalidad de ejercicio. Se define tal institución como la "prerrogativa del empleador en orden a no poner término a la relación laboral cuando el trabajador ha incurrido en una causal que justifique su despido". ${ }^{121}$

Para la Corte Suprema en la construcción de dicha teoría confluyen las ideas de la voluntad presunta y consolidación de situaciones. "Si el empleador nada hace para sancionar la falta o inconducta perpetrada por el trabajador dentro de un período más o menos inmediato o cercano a su comisión, se presume su voluntad de perdonarla", lo que también concurre "si aplicó una sanción de menor entidad, caso en el que se entremezclaría con el principio non bis in idem". ${ }^{122}$

Siguiendo a Montoya Melgar, podríamos sostener que la pasividad o tolerancia del empresario ante faltas continuas y conocidas crean un sentimiento de confianza en el infractor, por lo que si el empleador decide

\footnotetext{
117 Sobre el punto, v. Fernández Toledo, Raúl "La inmediatez en el ejercicio del poder disciplinario empresarial: perdón de la causal”, Revista Chilena de Derecho del Trabajo y de la Seguridad Social, 2014, vol. 5, No 9, pp. 243-258, y FernáNDEZ TOledo, "El poder disciplinario...", cit. (n. 5), pp. 445 y ss.

118 RoJas Miño, cit. (n. 38), p. 427.

119 Fernández Toledo, cit. (n. 5), p. 447.

120 Gamonal y Guidi, cit. (n. 34), p. 278.

121 C.S., 29 de noviembre de 2005, Rol 4.100-2004.

122 Por todos, C.S., 23 de julio de 2014, Rol 12514-2013.
} 
sancionar debe manifestarlo expresamente, comunicando al trabajador tal deseo. Esta comunicación se puede presuponer con la iniciación de una investigación que evidencia que éste ha salido de su inactividad, debiendo eso sí, ofrecer la posibilidad de defensa, ya que de otro modo estaríamos ante una hipótesis de mala fe consistente en el retraso desleal en la imposición de una sanción. ${ }^{123} \mathrm{El}$ inconveniente en nuestro modelo se da en la ausencia de norma expresa que consagre la exigencia de comunicar el inicio de un procedimiento de investigación previo a la imposición de la sanción disciplinaria.

No obstante, siguiendo a Fernández, creemos que existen argumentos suficientes para sostener lo contrario, proyectando la garantía del debido proceso ( $19 \mathrm{~N}^{\mathrm{o}} 3$ de nuestra Constitución Política) sobre el ejercicio del poder disciplinario del empleador ${ }^{124}$ y en concreto el derecho de defensa previo a la imposición de una sanción disciplinaria. ${ }^{125}$

Atendiendo el principio de buena fe y la naturaleza del despido disciplinario, esto es, por constituir una verdadera sanción privada con funciones equivalentes a las penas penales, como así también al hecho mismo de sancionar antes que a la calidad del sujeto, impone "el derecho de defensa del trabajador previo a la imposición de la sanción disciplinaria”. Este derecho se expresa en el conocimiento de la imposición de una sanción antes de su aplicación con el objeto de permitir su defensa ante los cargos formulados contra él, a fin de exonerarse la responsabilidad atribuida o disminuir la intensidad de la sanción, ${ }^{126}$ como bien se ha reconocido a nivel internacional, ${ }^{127}$ puesto que de otro modo se dejaría al trabajador en indefensión.

Por otro lado, un problema esencial será el determinar la ponderación de la inmediatez en el ejercicio de la sanción, en el orden a conocer cuando el silencio resulta o no significativo, al grado de constituir una condonación de la causal de despido.

Sobre el punto existe consenso jurisprudencial en que es necesaria una

123 V. Montoya Melgar, Alfredo, La buena fe en el derecho del trabajo, Tecnos, Madrid, 2001, pp. 84 y 85.

${ }^{124}$ Fernández Toledo, cit. (n. 5), pp. 274 y ss.

125 Ídem.

${ }^{126}$ Ibíd., pp. 280 y ss.

127 Artículo 7 del Convenio 158 de la Organización Internacional del Trabajo y los párrafos 7, 8, 9, 10, 11 y 13 de la Recomendación 119 sobre la terminación de la relación de trabajo de 1963, del mismo organismo. 
inmediatez ${ }^{128}$, oponiéndose a la prolongación excesiva de la sanción. ${ }^{129} \mathrm{La}$ jurisprudencia ha entendido como tiempo razonable para el ejercicio del poder sancionatorio un lapso de 30 días, ${ }^{130}$ teniendo siempre como presupuesto que el empleador esté en conocimiento de los hechos que configuran la causal de despido y se genere pasividad de su parte. ${ }^{131}$ De la misma forma se puede deducir un perdón tácito si el empleador manifiesta expresamente una conducta que supone una nueva oportunidad al trabajador. ${ }^{132}$

En otra línea a propósito de la inmediatez en la materialización del poder disciplinario, aparece una interrogante respecto de la oportunidad en su ejercicio frente a la hipótesis de carácter permanente, como lo podría ser el atraso reiterado. Indica al respecto un sector de la doctrina que el devenir del tiempo no implica perdón de la conducta, aún más cuando ésta no es grave, pero su habitualidad y proyección termina por configurar un incumplimiento de tal intensidad. ${ }^{133}$

En este punto diferimos, puesto que la conducta punible en estricto rigor se debe analizar y ponderar en la oportunidad de su concurrencia. Por lo mismo, la responsabilidad derivada de la misma se determina una vez que sea constatada, aplicándose una sanción de naturaleza conservativa del contrato cuando no se cumple con la tipología propia de la causal de despido. Incluso es más, una vez que se aplique una sanción, se extingue el poder disciplinario respecto de dichos hechos, ya que de otro modo se vulneraría los límites del poder disciplinario del empleador, en concreto el principio de non bis in idem. ${ }^{134}$

\section{Formalidades}

En cuanto a las formalidades de despido, el artículo 162 del C.T. regula tal situación. Cuando sea el empleador quien invoque la causal contenida en el artículo $160 \mathrm{~N}^{\mathrm{o}} 7$ del C.T. deberá comunicarlo por escrito al trabajador,

128 C.A. de Santiago, 8 de abril de 2008, Rol 166- 2008.

129 C.A. de Santiago, 2 de junio de 2006, Rol 6329-2005.

${ }_{130}$ C.S., 2 de diciembre de 2010, Rol 6161-2010; C.A. de Rancagua, 1 de julio de 2010, Rol N $76-$ 2010.

131 C.S., 1 de junio de 2010, Rol 1627-2010.; C.A. de Santiago, 22 de enero de 2015, Rol 1116-2014; C.A. de Iquique, 7 de febrero de 2011, Rol 104-2010.

132 Gamonal y Guidi, cit. (n. 34), p. 278.

133 Fernández Toledo, cit. (n. 5), p. 278.

134 En Chile, v. Fernández Toledo, Raúl, "Límites del poder disciplinario del empleador. Principios 'non bis in idem' y de proporcionalidad en la imposición de sanciones laborales", Revista Chilena de Derecho del Trabajo y de la Seguridad Social, 2013, Vol. 4, № 8, pp. 167-175. 
personalmente o por carta certificada enviada al domicilio señalado en el contrato, expresando la o las causales invocadas y los hechos en que se funda, teniendo un plazo de 3 días hábiles para informar. Deberá enviarse copia del aviso mencionado en el inciso anterior a la respectiva Inspección del Trabajo, dentro del mismo plazo.

Sobre la especificación que debe tener el contenido de la carta de despido, entendemos que el empleador dispone de una sola oportunidad previamente determinada para detallar los motivos de su despido, en la que debe señalar la causal de despido y los hechos en que se funda de manera detallada y específica. Si no lo hace se encontrará privado de invocarlos en un juicio posterior. Por el contrario, si pudiera invocarlos en su reclamo ante la inspección del trabajo o en una eventual contestación ante los tribunales de justicia, se dejaría al trabajador en la absoluta indefensión, al no tener la posibilidad de rebatirlos y desvirtuarlos, por no haber sido conocidos con anterioridad, vulnerando el debido proceso.

En este sentido nuestra jurisprudencia ha dicho que el solo hecho que el empleador omita precisión y especificación en los hechos fundantes, convierte al despido en injustificado, según lo dispuesto en el artículo 162 y 454 del C.T. ${ }^{135}$

Por su parte la Corte Suprema ha indicado que la carta además de indicar la causa legal, debe señalar "los hechos, conductas, comportamientos y circunstancias que la o las configuran". En directa relación con la anterior, la prueba que debe recaer en procedimiento sobre despido indebido o injustificado, debe versar únicamente sobre los hechos que se ha imputado al trabajador en la comunicación exoneratoria, quedando así vedado para el empleador alegar hechos distintos en el transcurso de la impugnación. ${ }^{136}$

\section{Impugnación del despido y procedimiento}

En cuanto a las reglas procedimentales bajo las que se va a sustanciar la acción destinada a discutir la aplicación justificada o injustificada de la causal, en principio se regirá conforme a las reglas del procedimiento ordinario laboral.

En el caso que exista un despido pluricausal en el que se produzca una vulneración de derechos fundamentales con ocasión del despido, se regirá

135 C.A. de Valparaíso, 3 de junio de 2009, Rol 148-2009; C.A. de San Miguel, 24 de septiembre de 2007, Rol 279-2007; C.A. de Santiago, 12 de septiembre de 2005, Rol 8708-2004.

136 V. C.S., 9 de junio de 2015, Rol 19352-2014. 
conforme a las normas del procedimiento de tutela, debiéndose interponerse la acción por despido injustificado (indebido) de manera subsidiaria a la acción de despido vulneratorio de derechos fundamentales, según lo ordenado en el artículo 489 del Estatuto Laboral.

El trabajador despedido tendrá un plazo de 60 días para impugnar el despido, el que puede verse suspendido por interposición de reclamo ante la inspección del trabajo correspondiente, el cual no podrá superar 90 días. ${ }^{137} \mathrm{Se}$ ha planteado, en base a la redacción de la norma, la exigencia de identidad sustancial entre lo reclamado en la Inspección del Trabajo y lo demandado posteriormente en los Tribunales de Justicia, en el sentido que, de no haber correspondencia en ambas oportunidades, esto es, de no haber reclamado de la legalidad del despido en la instancia administrativa, no podrá alegarse posteriormente la suspensión del plazo para interponer la demanda por despido injustificado, improcedente o indebido.

La Excma. Corte Suprema, pronunciándose sobre el punto, ha indicado que el artículo 168 del C.T. supone que la gestión en sede no jurisdiccional tiene como objetivo la prevención de conflictos, de manera que los términos del reclamo deben corresponderse con los sometidos al conocimiento de los tribunales de justicia para que se entienda que genera suspensión, de manera que de no verificarse la misma no puede operar la suspensión consagrada en la ley, toda vez que el sentido de la prórroga es evitar la intervención de la judicatura sobre los precisos y determinados puntos, mediante la obtención de una solución extrajudicial. ${ }^{138}$

Ahora, si bien se exige la correspondencia entre ambos, creemos oportuna la necesidad de determinar el grado de identidad que debe exigirse entre el reclamo en la Inspección del Trabajo y la demanda interpuesta en Tribunales de Justicia.

Sobre el punto es útil tener presente que el "concepto reclamo" no ha sido definido legalmente, por lo que debe entenderse en su sentido natural y obvio, esto es como una reclamación contra lo que es injusto, y que según los propios términos de la ley, y como así también lo ha entendido la jurisprudencia, se encuentra conformado por una serie de actuaciones y diligencias, que permiten calificarlo como un acto complejo ${ }^{139}$ y que por lo mismo no habrá que estar a la literalidad de los términos utilizados en su formulación, sino que las diversas

137 Artículo 168 del C.T.

138 C.S., 20 de abril de 2009, Rol 7805-2008.

139 C.S., 20 de septiembre de 2011, Rol 2027-2011. 
actuaciones y conceptos contemplados, para así develar su verdadero alcance.

En este contexto, en el evento en que se requiera la intervención de la autoridad administrativa, y se observe de los conceptos y prestaciones reclamadas que se ha solicitado la satisfacción de todos y cada uno de los aspectos propios del fin de la relación laboral, se debe entender "de manera inequívoca e indubitable", que también se reclama por la determinación de la causal, que conforme a la ley, tenga la capacidad de poner término al referido vínculo. ${ }^{140}$ Una interpretación contraria a la propuesta conllevaría el exigir un conocimiento técnico al trabajador que no tiene, lo que consecuencialmente vulneraría el principio protector en sus diversas manifestaciones.

En la misma línea, se produce un debate similar, ya que de acuerdo con el inciso segundo de su artículo 489 del C.T., la denuncia de tutela con motivo del despido deberá interponerse dentro del plazo de sesenta días contados desde la separación, "que se suspenderá en la forma a que se refiere el inciso final del artículo 168". No parece posible aplicar esa limitante, "desde que la vulneración puede llegar a ser tan amplia como la inconmensurabilidad de los derechos esenciales del trabajador y, por lo tanto, no es reductible a las causales de despido contempladas en el Título V del Libro I del cuerpo de leyes permanentemente citado, que hayan sido invocadas como legitimantes de la exoneración". Por lo mismo, el reenvío que efectúa el artículo 489 en su inciso segundo, al 168 en su parte final, ambos del C.T., lo es exclusivamente a la forma y no a la substancia, habida cuenta la imposibilidad de cotejo, en este plano, entre ambas normas, conforme antes se ha intentado dejar explicado. ${ }^{141}$

\section{Reparación}

Respecto a los efectos de la aplicación, ésta no da derecho a indemnizaciones por término de la relación laboral. No obstante, en el caso que los tribunales de justicia estimen que la causal es indebida, el juez condenará al empleador al pago de la indemnización por término de la relación laboral, esto es una indemnización sustitutiva de aviso previo y por años de servicio, viéndose esta última incrementada en un $80 \% .{ }^{142}$

Sobre la posibilidad de acumular una acción indemnizatoria de perjuicios

\footnotetext{
${ }^{140}$ Es la interpretación de la C.S., 20 de abril de 2009, Rol 7805-2008.

141 C.A. de Santiago, 18 de julio de 2013, Rol 790-2013. Se agradece al profesor Raúl Fernández Toledo por la facilitación de dicha sentencia y sus comentarios al respecto.

${ }^{142}$ Artículo 168 del C.T.
} 
morales por los daños producidos con ocasión del despido indebido, estimamos que existe absoluta compatibilidad, ya sea que se invoque conjuntamente con la acción de despido injustificado o conjuntamente con la acción de tutela por vulneración de derechos fundamentales, más aún cuando el recargo del 80\% constituye una indemnización sanción, constitutiva de una pena. ${ }^{143}$

En la primera hipótesis, esto es la acumulación de una indemnización de perjuicios morales producidos con ocasión del despido indebido con el incremento contemplado en el artículo 168 del C.T., como bien ha resuelto la Jurisprudencia de la E. Corte Suprema, no "se divisaría razón para, en la encrucijada, cerrar la puerta del procedimiento de general aplicación por causa de despido indebido, improcedente o injustificado, al anhelo reivindicatorio del mal moral", ${ }^{144}$ dejando atrás la tesis de la imposibilidad de demandar en sede laboral el resarcimiento de los perjuicios morales por terminación del contrato de trabajo. ${ }^{145}$

En la misma línea, no vemos inconveniente en acumular una acción por daño moral deducida con una acción por despido vulneratorio de derechos fundamentales con ocasión de un despido en el contexto de la impugnación de un despido fundado en el incumplimiento grave de las obligaciones del contrato de trabajo. Lo anterior ya sea cuando ésta conlleve una hipótesis pluricausal o bien de falsas imputaciones, que tenga como consecuencia un perjuicio de naturaleza moral en el trabajador despedido, por cuanto como bien se ha dicho, las indemnizaciones de 6 a 11 remuneraciones contempladas en el artículo 489 del C.T., son de naturaleza punitiva o sancionatoria ${ }^{146}$, por lo que en ningún momento logran resarcir el perjuicio de naturaleza moral producido por el despido vulneratorio de derechos fundamentales.

Una interpretación que restrinja dicha acción o que promueva la incompatibilidad, contraría el principio constitucional de reparación integral

143 Rojas MiÑo, Irene, "La naturaleza jurídica de la indemnización por término de contrato de trabajo en el ordenamiento laboral chileno", Revista de Derecho, P. Universidad Católica de Valparaíso, 2013, $\mathrm{N}^{\mathrm{o}} 41$ (dic.), pp. 107-143; p. 142.

144 C.S., 7 de octubre de 2014, Rol 2746-2014.

145 Para una mayor profundización, véase Gamonal Contreras, Sergio, El daño moral en el contrato de trabajo, Legal Publishing, Santiago, 2007; Gamonal Contreras, Sergio, "Evolución del daño moral por término del contrato de trabajo en el derecho chileno", Revista de Derecho, P. Universidad Católica de Valparaíso, 2012, № 39 (dic.), pp. 161-176.

146 Ugarte Cataldo, José L., Tutela de derechos fundamentales del trabajador, LegalPublishing, Santiago, 2009, p. 90; Ugarte Cataldo, José L., El derecho a la no discriminación en el trabajo, Thomson Reuters, Santiago, 2013, pp. 84 y ss. En sentido contrario, Gamonal Contreras, Sergio, El procedimiento de tutela de derechos laborales, LexisNexis, Santiago, 2008, p. 39; Gamonal y Guidi, cit. (n. 34), p. 316. 
del daño, ${ }^{147}$ máxime si la infracción en que se funda la acción de tutela se encuentra en un derecho fundamental distinto a la integridad síquica y física del actor. De ser así no solo se afectaría el mentado principio de reparación integral, sino también el de tutela judicial efectiva.

Aún más, incluso la doctrina que entiende que la indemnización contemplada en el procedimiento tiene por objeto resarcir los perjuicios morales, ${ }^{148}$ indica también que hay casos excepcionales en los cuales debe ser complementada con una indemnización adicional, ${ }^{149}$ cuando ésta no logra resarcir la totalidad de los perjuicios causados por su tarifación. Sin compartir la idea de naturaleza moral tarifada de esta indemnización, creemos lógica la excepción propuesta por la doctrina, más aún si la cuantificación del perjuicio se determinará por la remuneración del trabajador y no por el perjuicio efectivamente sufrido, lo cual constituye un argumento más para rechazar la idea de una naturaleza reparadora de la indemnización contemplada en el 489 del C.T.

\section{CONCLUSIONES}

1. La configuración de doctrina y jurisprudencia en Chile respecto del despido por incumplimiento grave de las obligaciones que impone el contrato de trabajo, ha oscilado en la determinación de su naturaleza entre el despido como una resolución contractual y una sanción laboral.

Lo anterior ha permitido establecer una serie de requisitos y elementos para la determinación y ponderación de la justificación en la aplicación de causa de despido, tanto por requisitos propios del derecho de los contratos como por del derecho de las sanciones, predominando esencialmente esta última.

2. En tal contexto, debido a su amplia redacción causal y referencia a un contenido obligacional diverso, como así también a la textura abierta y conceptos jurídicos determinados que configuran su tipología causal, el motivo de despido en estudio se ha caracterizado como una hipótesis de despido con un contenido flexible, de carácter genérico y polivalente, que comprende muchas veces diversas situaciones fácticas que no encuentran un correlato en causales tipificadas, produciendo una absorción de motivos de despidos imperfectos que

147 Domínguez Águlla, Ramón, "Reparación del daño moral por despido injustificado", Revista Chilena de Derecho, 1998, 25, 2, p. 441.

148 Gamonal Contreras, cit. (n. 146), p. 39; Gamonal y Guidi, cit. (n. 34), p. 316.

149 Gamonal Contreras, "Evolución...”, cit. (n. 145), p. 174. Con mayor detalle Gamonal Contreras, Sergio, "El daño moral en el artículo 489 del Código del Trabajo", Revista de derecho (Valparaíso), 2016, (47), pp. 305-327. 
no tienen cabida en motivos de contornos más definidos.

No obstante lo anterior, la propia jurisprudencia ha fijado criterios para una correcta ponderación de la gravedad del incumplimiento para la calificación de la intensidad del incumplimiento, debiendo verificarse por el sentenciador el carácter aislado de la situación, la alteración al funcionamiento y estabilidad de la empresa, perjuicio económico, la cantidad de años que el trabajador lleva prestando servicios, los antecedentes laborales, la gradualidad de la sanción (correspondencia entre la falta y su sanción) y la conducta anterior del trabajador.

3. Respecto de las formalidades e impugnación judicial, existe claridad sobre sus limitaciones y alcance, sin perjuicio de conflictos interpretativos sobre la suspensión de plazos de interposición.

Respecto de los recursos judiciales que puedan interponerse frente a la sentencia judicial que resuelve un juicio por despido fundado en el incumplimiento grave de las obligaciones, no existe claridad jurisprudencial al respecto, asociado principalmente en la determinación o no como una cuestión de hecho o derecho.

4. En cuanto a la reparación del mismo, existe consenso en que un despido por incumplimiento grave de las obligaciones puede generar perjuicios morales y que éstos no se encuentran comprendidos en los recargos sancionatorios. A su vez, existe consenso en la compatibilidad de acciones con el procedimiento de tutela y sus indemnizaciones, sin perjuicio de la divergencia respecto de la satisfacción del perjuicio causado en base a la naturaleza atribuida a las indemnizaciones fijadas para la vulneración de derechos fundamentales con el despido.

\section{BIBLIOGRAFÍA}

Aguilera Izquierdo, R., Las causas del despido disciplinario y su valoración por la Jurisprudencia, Aranzadi Editorial, Madrid, 1997.

Albiol Montesinos, I., El despido disciplinario y otras sanciones en la empresa, Ediciones Deusto S.A., Bilbao, 1990.

Alonso Olea, M. El despido, Ediciones Deusto S.A., Madrid, 1958, Instituto de Estudios Políticos.

Astudillo Contreras, O., El recurso de Nulidad Laboral. Algunas consideraciones técnicas, Thomson Reuters, Santiago, 2012.

Ballester Laguna, F., La condición más beneficiosa. Caracterización y eficacia de las mejoras contractuales, Comares, Granada. 2001. 

2008

Barahona Estay, Francisca, Despido Indirecto, Ed. Puntolex, Santiago,

Baylos Grau, A., Autoridad y democracia en la empresa, Madrid, Trotta, 1992.

Baylos Grau, A., derecho del trabajo: modelo para armar, Madrid, Trotta, 1991.

Baylos Grau, A.; Pérez Rey, J., El despido o la violencia del poder privado, Trotta, Madrid, 2009.

Baylos Grau, A., "Consideraciones sobre el despido individual y la garantía judicial del derecho al trabajo", Revista de Derecho Social, No 46, 2009. pp. 11-30.

Calvo Gallego, F., Códigos Éticos y Derechos de los Trabajadores. Una aproximación a la práctica en las empresas españolas, Bomarzo, Albacete, 2008.

Cremades Sanz-Pastor, B., La sanción disciplinaria en la empresa, Instituto Estudios Políticos, Madrid, 1969.

Domínguez Águila, R., "Reparación del daño moral por despido injustificado", Revista Chilena de Derecho, 1998, 25, 2.

Domínguez Montoya, A., "Análisis crítico al Derecho del Trabajo: entre el paternalismo y la emancipación”, Revista de Estudios Ius Novum, 2012, No 5.

Domínguez Montoya, A.; Mella Cabrera, P., "El Recurso de Nulidad Laboral", Revista de Derecho Universidad de Concepción, 2011, N²29-230. año LXXIX.

Domínguez Montoya, A.; Mella Cabrera, P., "Trabajo y Derecho: un padre ausente, el conflicto social", Revista de Derecho Universidad Católica del Norte (RUCN), 2015, vol. 22, $\mathrm{N}^{\mathrm{o}} 1$.

FERNÁNDEZ LóPEZ, M. F, El poder disciplinario en la empresa, Editorial Civitas S.A., Madrid, 1991.

Fernández Toledo, R., "Límites del poder disciplinario del empleador. Principios 'non bis in idem' y de proporcionalidad en la imposición de sanciones laborales", Revista Chilena de Derecho del Trabajo y de la Seguridad Social, 2013, Vol. 4, No 8, pp. 167-175.

Fernández Toledo, R. "La inmediatez en el ejercicio del poder disciplinario empresarial: perdón de la causal", Revista Chilena de Derecho del Trabajo y de la Seguridad Social, 2014, vol. 5, No 9.

Fernández Toledo, R., "El poder disciplinario del empleador: Configuración jurídica de la sanción laboral que puede imponer al trabajador dependiente", Revista de Derecho P. Universidad Católica de Valparaíso, 2015, Vol. 44. pp. 423-460.

FERnÁndez Toledo, R., El poder disciplinario del empleador. Thomson Reuters - La Ley, Santiago, 2016. 
Foucault, M., La verdad y las formas jurídicas, Gedisa, Barcelona, 1995.

Foucault, M., Defender la Sociedad. Curso en el Collège de France (1975-1976), FCE, México D.F., 2006.

Foucault, Michel, Historia de la Sexualidad. La voluntad del saber, Ed. Siglo XXI, Buenos Aires, 2007, pp. 74 y ss. 2008.

Foucault, M., Nietzsche, la Genealogía, la Historia, Pre-textos, Valencia,

Foucault, M., Vigilar y castigar. Nacimiento de la prisión, Siglo XXI Editores, Buenos Aires, 2002.

Gamonal Contreras, S., El daño moral en el contrato de trabajo, Legal Publishing, Santiago, 2007.

Gamonal Contreras, S., El procedimiento de tutela de derechos laborales, LexisNexis, Santiago, 2008.

Gamonal Contreras, S., Fundamentos del Derecho del Trabajo, Lexis Nexis, Santiago, 2008.

Gamonal Contreras, S., "Evolución del daño moral por término del contrato de trabajo en el derecho chileno", Revista de Derecho P. Universidad Católica de Valparaíso, 2012, Vol. 39.

Gamonal Contreras, Sergio, "El daño moral en el artículo 489 del Código del Trabajo", Revista de Derecho P. Universidad Católica de Valparaíso, 2016, (47), pp. 305-327.

Gamonal Contreras, S.; Guid Moggia, C., Manual del Contrato de Trabajo, Legal Publishing, Santiago, 2011.

Gil y GiL, J.L, "El concepto de despido disciplinario", en Martín Jiménez, R.; Sempere Navarro, A. (Coords.), El Despido: aspectos sustantivos y procesales, Editorial Aranzadi, Madrid, 2004.

Gómez Abelleira, Francisco, La Causalidad del Despido Disciplinario, Thomson Reuters, Madrid, 2009.

GonzÁlez-Posada Martínez, E., "La noción de incumplimiento contractual grave y culpable en la Jurisprudencia”, en Gil y Gil, J.; Manuel del Valle, J. (Coords.), El despido disciplinario: Homenaje al Profesor Juan Antonio Sagardoy Bengoechea, Cinca, Madrid, 2009.

Guerrero Ostolaza, J. M., "La desobediencia e indisciplina en el trabajo", en Gil y Gil, J.; Manuel del Valle, J. (Coords.), El despido disciplinario: Homenaje al Profesor Juan Antonio Sagardoy Bengoechea, Cinca, Madrid, 2009.

ItURRA TAPIA, M., "Aspectos laborales relacionados con el cheque con especial mención a la terminación del contrato de trabajadores bancarios, motivado en protestos de cheques personales". Memoria de prueba para optar al grado de Licenciatura en Ciencias Jurídicas y Sociales. Universidad de Chile, 2007. 
Kahn-Freund, O., Trabajo y Derecho, Ministerio de Trabajo y Seguridad Social, Madrid, 1987.

Lizama Portal, L., Derecho del Trabajo, LexisNexis, Santiago, 2005.

MARTín Valverde, Antonio, "Ideologías jurídicas y contrato de trabajo", en AA.VV., Ideología y relaciones de trabajo, Publicaciones Universidad de Sevilla, Sevilla, 1978.

Martín VAlverde, A., "Cuestiones actuales sobre el despido disciplinario", en Gárate Castro F., Estudios ofrecidos al profesor Manuel Alonso Olea, con motivo de investidura como doctor "honoris causa" por la Universidad de Santiago de Compostela, Santiago de Compostela, 1997.

Melis Valencia, C.; Sáez Carlier, F., El Contrato Individual de Trabajo en los Dictámenes de la Dirección del Trabajo, Ed. Jurídica Conosur, Santiago, 2009.

Mella Cabrera, P.; "El despido indirecto o resolución del contrato de trabajo por incumplimiento patronal", Revista de Derecho Universidad de Concepción, 2001, № 210 (Jul-Dic), pp. 95-102

Monereo Pérez, José L.; Fernández Avilés, José A., "La reconfiguración causal del despido colectivo: algunas reflexiones críticas", en Castiñeira Fernández, J. (Coord.), Presente y futuro de la regulación del despido, Aranzadi, Madrid, 1997.

Montoya Melgar, A., "Dirección y Control de la actividad laboral", en Borrajo Dacruz (director). Comentarios a las leyes laborales. El estatuto de los trabajadores, Ed. Edersa, Madrid, 1985, Tomo V.

Montoya Melgar, A., La buena fe en el derecho del trabajo, Tecnos, Madrid, 2001.

Nadal Serri, D., El despido en el Código del Trabajo, Lexis Nexis, Santiago, 2003.

Rodríguez PIÑERo, M., "El despido disciplinario y la 'modernización' del Derecho del Trabajo", en Gil y Gil, J.; Manuel del Valle, J. (Coords.), El despido disciplinario: Homenaje al Profesor Juan Antonio Sagardoy Bengoechea, Cinca, Madrid, 2009.

Rodríguez-Piñero y Bravo-Ferrer, M., "Derecho, Trabajo y despido", Relaciones laborales. 1997, No 1, pp. 1-9.

RoJAs MiÑo, I., "La naturaleza jurídica de la indemnización por término de contrato de trabajo en el ordenamiento laboral chileno", Revista de Derecho, P. Universidad Católica de Valparaíso, 2013, No 41 (dic.), pp. 107-143.

Rojas Miño, I., Derecho del Trabajo. Derecho Individual del Trabajo, Thomson Reuters, Santiago, 2015.

Serra Domínguez, M., Estudio de Derecho Procesal, Editorial Ariel, Barcelona, 1969. 
Sinzheimer, H., "La esencia del Derecho del Trabajo", en Sinzheimer, H. (Coord.), Crisis económica y derecho del trabajo; cinco estudios sobre la problemática humana y conceptual del derecho del trabajo, Ministerio de Trabajo y Seguridad Social, Madrid, 1984.

Thayer Arteaga, W.; Novoa Fuenzalida, P., Manual de Derecho del Trabajo, III, Editorial Jurídica de Chile, Santiago, 1980.

Ugarte Cataldo, J.L., "El contenido del Contrato individual de Trabajo", Boletín Oficial de la Dirección del Trabajo, 1996, No 94 (nov).

Ugarte Cataldo, J.L., Tutela de derechos fundamentales del trabajador, LegalPublishing, Santiago, 2009.

Ugarte Cataldo, J.L., El derecho a la no discriminación en el trabajo, Thomson Reuters, Santiago, 2013.

Vargas Miranda, R., Terminación del Contrato de Trabajo, II, Editorial Metropolitana, Santiago, 2014.

Vivanco Cisternas, M., El Despido Laboral, Editorial Jurídica de Chile, Santiago, 1994.

Walker Errázuriz, Francisco, Terminación del contrato de trabajo, Cepet, Santiago, 1990. 